\title{
Calculation of Standard Thermodynamic Potentials for Na-Zeolites with the Use of Linear Programming Problems
}

\author{
Oleg Viacheslavovich Yeriomin \\ Establishment of the Russian Academy of Sciences, Institute of Natural Resources, Ecology, and Cryology, \\ The Siberian Branch of the Russian Academy of Sciences, Chita, Russian Federation \\ E-mail: yeroleg@yandex.ru \\ Received April 1, 2011; revised June 2, 2011; accepted July 6, 2011
}

\begin{abstract}
Linear programming problems for Na-Al-Si-O-H system have been formulated and solved for calculations of standard enthalpies and Gibbs potentials of zeolites with unknown thermodynamic properties. The calculations are based on dual solutions of linear programming problems. Comparison of numerical results with published data gives relative mistakes of estimations less than one percent. On the basis of calculated potentials the standard entropies have been estimated. The standard thermodynamic potentials for eight natural zeolites with unknown properties have been calculated. The presented method does not demand any information about crystal structure of zeolites and can be applied to any of their stoichiometric presentation.
\end{abstract}

Keywords: Na-Zeolites, Standard Thermodynamic Potentials, Linear Programming

\section{Introduction}

Zeolites are very important aluminosilicate microporous substances of multipurpose usage. Possessing specific framework they actively participate in processes of sorption and ion exchange, catalysis, that has caused their wide application in the industry, agriculture, medicine, environment protection.

The knowledge of thermodynamic properties of zeolites provides the investigations of their behaviour in nature, technological and biochemical processes, in synthesis of new materials.

Alongside with experimental methods of determination of physical-chemical properties of zeolites there are some predictive methods now available. One group of methods is based on the additivity of oxides (or hydroxides) components of zeolites [1]. These models have a good accuracy for anhydrous forms but in cases with zeolitic water the divergence of estimations is more significant. Another group of methods uses the framework data of zeolites [2].

Whereas natural and synthesized zeolites are often presented by stoichiometry variable compounds the role of empirical methods of calculation of their thermodynamic properties is very important.

Methods of thermodynamic modelling in geochemistry allow to analyze the physical and chemical properties of systems and components on the basis of dual theorems in convex programming [3]. With the use of linear programming problems for complex copper sulfates the relative mistakes of standard Gibbs potentials calculation have been obtained at about 1\% [4]. We'll consider the application of linear programming methods for an estimation of thermodynamic potentials for Na-zeolites.

\section{Methodology}

For five chemical elements Na-Al-Si-O-H we'll construct the set $S$ from six substances including zeolites in such a way that stoichiometric matrix $A$ has a full rank. Then for $S$ it is possible to write down the unique chemical reaction [5]. For example, for

$S=\left\{\mathrm{NaAlSi}_{2} \mathrm{O}_{6} \cdot \mathrm{H}_{2} \mathrm{O}\right.$ (analcime); $\mathrm{NaAlSi}_{2} \mathrm{O}_{6}$ (dehydrated analcime); $\mathrm{Na}_{2} \mathrm{Al}_{2} \mathrm{Si}_{3} \mathrm{O}_{10} \cdot \mathrm{H}_{2} \mathrm{O}$ (natrolite); NaAl$\mathrm{SiO}_{4}$ (nefeline); $\mathrm{NaAl}_{3} \mathrm{Si}_{3} \mathrm{O}_{10}(\mathrm{OH})_{2}$ (paragonite); $\mathrm{O}_{2}$ \} reaction can be written:

$$
\begin{aligned}
& \mathrm{NaAlSi}_{2} \mathrm{O}_{6}+\mathrm{Na}_{2} \mathrm{Al}_{2} \mathrm{Si}_{3} \mathrm{O}_{10} \cdot 2 \mathrm{H}_{2} \mathrm{O} \\
& =2 \mathrm{NaAlSi}_{2} \mathrm{O}_{6} \cdot \mathrm{H}_{2} \mathrm{O}+\mathrm{NaAlSiO}_{4}
\end{aligned}
$$

Let's define a following linear programming problem:

$$
\min \Delta_{f} H^{\circ} x, A x=b, x \geq 0,
$$

where $\Delta_{f} H^{\circ}$-values of standard enthalpy formation from elements for substances from $S$, 
$x$ - vector of their quantity,

$b$ - vector of chemical elements mass balance.

If $x^{*}$ is a nonsingular solution of (2), then:

$$
\Delta_{f} H^{\circ} x^{*}=b^{*},
$$

where $y^{*}$-solution of equivalent to (2) dual problem [6]:

$$
\max b y, A^{\prime} y \leq \Delta_{f} H^{\circ},
$$

where '- index of transposing.

If $x^{*}$ contains nonzero quantity of any zeolite $x_{z}^{*}>0$, then from (3) follows:

$$
\Delta_{f} H^{\circ}(z)=A(z) y^{*},
$$

where $\Delta_{f} H^{\circ}(z)$-the potential of zeolite $z$ at equilibrium, $A(z)$-vector-column of $A$ matrix, corresponding to stoichiometric formula of zeolite $z$.

Equality (5), namely the $y^{*}$ value can be used for calculation of unknown $\Delta_{f} H^{\circ}(z)$ for Na-zeolites by means a formula:

$$
\Delta_{f} H^{\circ}(z)=Y(z) y^{*},
$$

where $Y(z)$-stoichiometric vector of zeolite $z$.

Let's consider a numerical example.

The $\Delta_{f} H^{\circ}$ values for component $S$ according to their written sequence are taken from [7]:

$\Delta_{f} H^{\circ}=-(3291100,2974800,5718600,2073800$, 5943500 , 0) $\mathrm{J} /$ mole.

Vector of mass balance is defined by reaction (1):

$b=\left(b_{N a}, b_{A l}, b_{S i}, b_{O}, b_{H}\right)=(3,3,5,18,4)$ mole.

The problem (2) has solution: $x^{*}=(0,1,1,0,0,0)$ mole - mole of dehydrated analcime and mole of natrolite.

The problem (4) has solution:

$y^{*}=\left(y_{N a}^{*}, y_{A l}^{*}, y_{S i}^{*}, y_{O}^{*}, y_{H}^{*}\right)=(32157,-380213,-26705$, -428889, 51073) $\mathrm{J} / \mathrm{mole}$.

The equation (6) for dachiardite can be written:

$$
\begin{aligned}
& \Delta_{f} H^{\circ}\left(\mathrm{Na}_{4} \mathrm{Al}_{4} \mathrm{Si}_{20} \mathrm{O}_{48} \cdot 13 \mathrm{H}_{2} \mathrm{O}\right) \\
&=\mathrm{Y}\left(\mathrm{Na}_{4} \mathrm{Al}_{4} \mathrm{Si}_{20} \mathrm{O}_{48} \cdot 13 \mathrm{H}_{2} \mathrm{O}\right) \mathrm{y}^{*} \\
&=(4,4,20,61,26) \\
&(32157,-380213,-26705,-428889,51073) \\
&=-26760655(\mathrm{~J} / \mathrm{mole}) .
\end{aligned}
$$

Similarly we'll evaluate the $\Delta_{f} G^{\circ}$ values in (2). For data [7]:

$\Delta_{f} G^{\circ}=-(3291100,2974800,5718600,2073800$, $5943500,0) \mathrm{J} / \mathrm{mole}$,

solution (2): $x^{*}=(0,1,1,0,0,0)$ mole, solution (4): $y^{*}=\left(y_{N a}^{*}, y_{A l}^{*}, y_{S i}^{*}, y_{O}^{*}, y_{H}^{*}\right)=(19309$, -358452, -29039, -401930, 67990) J/mole.

Gibbs potentials and enthalpies are connected with standard entropies $S^{\circ}$. We'll use the thermodynamic data consistency equation of "Selektor" software [3] for calculation of $S^{\circ}$ :

$$
S^{\circ}=\left(\Delta_{f} H^{\circ}-\Delta_{\mathrm{f}} \mathrm{G}^{\circ}\right) / \mathrm{T}+\mathrm{L},
$$

where $T$ - temperature (298.15 K), $L=Y(z) s^{\circ}$, $s^{\circ}=\left(s_{N a}^{\circ}, s_{A l}^{\circ}, s_{S i}^{\circ}, s_{O}^{\circ}, s_{H}^{\circ}\right)=(51.2,28.3,18.8,102.5,65.0)$ $\mathrm{J} / \mathrm{mole} / \mathrm{K}$. Values of $s^{\circ}$ - entropies of chemical elements are taken from [8].

Results of calculations on (6) and (7) and comparison with published data [7] are presented in Table 1.

\section{Results and Discussion}

The set $\mathrm{S}$ defines the forms of problems (2). The choice of components $\mathrm{S}$ is rather arbitrary. It is desirable that the included zeolites have experimental or estimated thermodynamic data. The condition of full rank $A$ matrix allows to make the preliminary chemical interpretation of system. The problem (2) for Gibbs energy can be considered as thermodynamic equilibrium calculation for the heterogeneous mixture $\mathrm{S}$ under standard temperature and pressure. The solutions of (2) define zeolites for which the condition (5) will be satisfied. They can be named "basic" zeolites - on the basis of which the estimation on (6) will be applied for other substances. Natrolite and dehydrated analcime are the "basic" zeolites in our calculations. We can see from Table 1 the implementation of an optimality criterion (5) - exact equality of thermodynamic potentials for "basic" zeolites.

For the existing solution $y^{*}$ the calculation of unknown enthalpies (or Gibbs energies) of substances by means (6) is simple and represents the scalar multiplication of two vectors. For any stoichiometric forms of zeolites the use of (6) gives the molal dimension of potentials. As a example, the estimations on (6) and comparison with calorimetry measurements [10] for some hydrous and anhydrous forms of sodalite family zeolites are presented in Table 2.

The calculated on (6) and (7) thermodynamic potentials for some natural Na-zeolites [11] with unknown properties are presented in Table 3. These data may be used in geochemical calculations of processes with their participation.

The vector $\mathrm{y}^{*}$ can be considered as the chemical elements contributions to potentials of zeolites. The enthalpy solution of (2) $-y^{*}$ are presented as a bar diagram on Figure 1. We can see from figure that oxygen and aluminium atoms provide the most contributions in enthalpy potentials. Hydrogen and sodium have a positive energy values.

The stability of calculations on (6) depends on variability of $\mathrm{y}^{*}$ components in connection with data uncertainty for "basic" zeolites. This problem demands the 
Table 1. Values of standard thermodynamic potentials for some Na-zeolites calculated on (6) and (7). In brackets - a relative mistakes of calculations (\%) with published data $[7,9]$.

\begin{tabular}{|c|c|c|c|c|c|c|}
\hline \multirow[b]{2}{*}{ Chemical formula (mineral) } & \multicolumn{3}{|c|}{ [7] } & \multicolumn{3}{|c|}{ Calculated on (6) and (7) } \\
\hline & $\begin{array}{c}-\Delta_{f} G^{\circ} \\
(\mathrm{kJ} / \mathrm{mole})\end{array}$ & $\begin{array}{c}-\Delta_{f} H^{\circ} \\
\text { ( kJ/mole) }\end{array}$ & $\begin{array}{c}S^{\circ} \\
(\mathrm{J} / \mathrm{mole} / \mathrm{K})\end{array}$ & $\begin{array}{c}-\Delta_{f} G^{\circ} \\
\text { ( kJ/mole) }\end{array}$ & $\begin{array}{c}-\Delta_{f} H^{\circ} \\
(\mathrm{kJ} / \mathrm{mole})\end{array}$ & $\begin{array}{c}S^{\circ} \\
(\mathrm{J} / \mathrm{mole} / \mathrm{K})\end{array}$ \\
\hline $\mathrm{NaAlSi}_{2} \mathrm{O}_{6}$ (dehydrated analcime) & 2808.8 & 2974.8 & 175.4 & $\begin{array}{c}2808.8 \\
(0)\end{array}$ & $\begin{array}{c}2974.8 \\
(0)\end{array}$ & $\begin{array}{l}174.5 \\
(0.5)\end{array}$ \\
\hline $\mathrm{Na}_{2} \mathrm{Al}_{2} \mathrm{Si}_{3} \mathrm{O}_{10} \cdot \mathrm{H}_{2} \mathrm{O}$ (natrolite) & 5316.6 & 5718.6 & 359.7 & $\begin{array}{c}5316.6 \\
(0)\end{array}$ & $\begin{array}{l}5718.6 \\
(0)\end{array}$ & $\begin{array}{c}356.9 \\
(1.0)\end{array}$ \\
\hline $\mathrm{NaAlSi}_{2} \mathrm{O}_{6} \cdot \mathrm{H}_{2} \mathrm{O}$ (analcime) & 3068.3 & 3291.1 & 234.3 & $\begin{array}{c}3074.7 \\
(0.2)\end{array}$ & $\begin{array}{c}3301.5 \\
(0.3)\end{array}$ & $\begin{array}{l}210.3 \\
(11.4)\end{array}$ \\
\hline $\mathrm{Na}_{4} \mathrm{Al}_{4} \mathrm{Si}_{20} \mathrm{O}_{48} \cdot 3 \mathrm{H}_{2} \mathrm{O}$ (dachiardite) [9] & 24724.0 & 26723.0 & 1947 & $\begin{array}{c}24687.3 \\
(0.1)\end{array}$ & $\begin{array}{c}26760.6 \\
(0.1)\end{array}$ & $\begin{array}{l}1919 \\
(1.5)\end{array}$ \\
\hline
\end{tabular}

Table 2. The standard enthalpies of formation from elements $-\Delta_{f} H^{\circ} \quad$ (kJ/mole) of some hydrous and anhydrous forms of sodalite family materials [10]. In brackets—mistakes of calculations on (6).

\begin{tabular}{ccc}
\hline Chemical formula & $-\Delta_{f} H^{\circ} \mathrm{kJ} / \mathrm{mole}$ & Calculated on (6) \\
\hline $\mathrm{Na}_{7.82}(\mathrm{OH})_{1.84}\left[\mathrm{Al}_{5.98} \mathrm{Si}_{6.02} \mathrm{O}_{24}\right]\left(\mathrm{H}_{2} \mathrm{O}\right)_{3.27}$ & 14275.4 & $14239.9(0.2)$ \\
$\mathrm{Na}_{7.82}(\mathrm{OH})_{1.84}\left[\mathrm{Al}_{5.98} \mathrm{Si}_{6.02} \mathrm{O}_{24}\right]$ & 13181.7 & $13171.5(0.1)$ \\
$\mathrm{Na}_{7.60}(\mathrm{OH})_{1.64}\left[\mathrm{Al}_{5.96} \mathrm{Si}_{6.04} \mathrm{O}_{24}\right]\left(\mathrm{H}_{2} \mathrm{O}\right)_{3.00}$ & 14093.2 & $14076.2(0.1)$ \\
$\mathrm{Na}_{7.60}(\mathrm{OH})_{1.64}\left[\mathrm{Al}_{5.96} \mathrm{Si}_{6.04} \mathrm{O}_{24}\right]$ & 13085.1 & $13095.9(0.1)$ \\
\hline
\end{tabular}

Table 3. The standard thermodynamic potentials of some natural Na-zeolites calculated on $(6,7)$.

\begin{tabular}{cccc}
\hline Chemical formula (mineral) & $-\Delta_{f} G^{\circ}, \mathrm{kJ} /$ mole & $-\Delta_{f} H^{\circ}, \mathrm{kJ} / \mathrm{mole}$ & $S^{\circ}, \mathrm{J} / \mathrm{mole} / \mathrm{K}$ \\
\hline $\mathrm{Na}_{8} \mathrm{Al}_{6} \mathrm{Si}_{6} \mathrm{O}_{24}(\mathrm{OH})_{2} \cdot 3 \mathrm{H}_{2} \mathrm{O}$ (cancrinite) & 13282.5 & 14170.7 & 1205.8 \\
$\mathrm{Na}_{8} \mathrm{Al}_{8} \mathrm{Si}_{16} \mathrm{O}_{48} \cdot 22 \mathrm{H}_{2} \mathrm{O}$ (gmelinite) & 28321.3 & 30947.0 & 2120.6 \\
$\mathrm{NaAlSi} \mathrm{O}_{12} \cdot 3 \mathrm{H}_{2} \mathrm{O}$ (mordenite) & 6105.3 & 6649.6 & 449.8 \\
$\mathrm{Na}_{2} \mathrm{Al}_{2} \mathrm{Si}_{3} \mathrm{O}_{10} \cdot 3 \mathrm{H}_{2} \mathrm{O}$ (paranatrolite) & 5582.5 & 6037.9 & 390.3 \\
$\mathrm{Na}_{8} \mathrm{Al}_{6} \mathrm{Si}_{6} \mathrm{O}_{24}(\mathrm{OH})_{2}$ (sodalite) & 12484.7 & 13212.7 & 908.7 \\
$\mathrm{Na}_{5} \mathrm{Al}_{5} \mathrm{Si}_{11} \mathrm{O}_{32} \cdot 1 \mathrm{H}_{2} \mathrm{O}$ (gobbinsite) & 17802.3 & 19364.2 & 1298.4 \\
$\mathrm{Na}_{1.6} \mathrm{Al}_{1.5} \mathrm{Si}_{36} \mathrm{O}_{72} \cdot 18 \mathrm{H}_{2} \mathrm{O}$ (heulandite) & 35278.2 & 38653.1 & 2788.2 \\
$\mathrm{NaAlSi}_{3} \mathrm{O}_{8} \cdot 3.5 \mathrm{H}_{2} \mathrm{O}$ (zeolite) & 4572.5 & 5008.4 & 348.4 \\
\hline
\end{tabular}

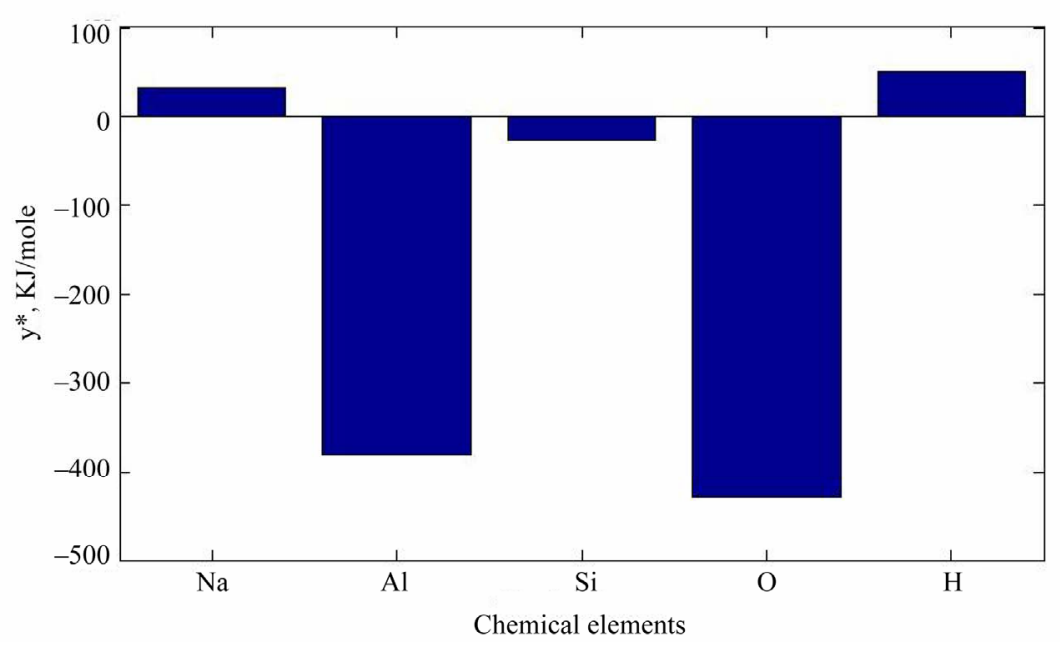

Figure 1. The enthalpy potentials of chemical elements for Na-zeolites. 
supplementary analysis. For our example, the handbook [7] contains one enthalpy value for natrolite, and difference between maximum and minimum values for dehydrated analcime is $15.4 \mathrm{~kJ} /$ mole $(\sim 0.6 \%)$. For this uncertainty the divergence of estimations on (6) for all considered in article substances does not exceed $1 \%$.

Evaluation on (6) gives for all Na-zeolites enthalpy value of zeolitic water equal to $-326.7 \mathrm{~kJ} / \mathrm{mole}$. This energy of water is more preferable that ones in structure of ice-I -292.7 kJ/mole [12].

The considered method has restriction in the applicability only to Na-zeolites, but can be extended by addition in system of calcium, magnesium and (or) others chemical elements.

\section{Conclusions}

The method of calculation standard thermodynamic po- tentials for Na-zeolites has been proposed on the basis of dual solutions of linear programming problems. The re- sults of estimation have acceptable accuracy with pub- lished experimental and predicted data. The presented method does not demand any information about crystal structure of zeolites and can be applied to any of their stoichiometric presentation.

\section{References}

[1] J. Shi, G. Lu and G. Cao, "A New Method of Estimating Standard Enthalpies of Formation of Zeolites,” Journal of Porous Materals, Vol. 15, No. 5, 2008, pp. 513-517. doi:10.1007/s10934-007-9105-7

[2] R. Mathieu and Ph. Vieillard, “A Predictive Model for the Enthalpies of Formation of Zeolites," Microporous and Mesoporous Materials, Vol. 132, No. 3, 2010, pp. 335-351.doi:10.1016/j.micromeso.2010.03.011

[3] K. V. Chudnenko, "Thermodynamic Modelling in Geo- chemistry: The Theory, Algorithms, Software, Examples,” in Russian, Publishing house GEO, Novosibirsk, 2010, p. 287.

[4] O. V. Yeriomin, S. V. Vinnichenko and G. A. Yurgenson, "Evaluation of Standard Gibbs Potentials for Copper Hydroxosulfate Hydrates from Solutions of Dual Linear Programming Problems," in Russian, Doklady Akademii Nauk, Vol. 409, No. 3, 2006, pp. 386-388.

[5] N. F. Stepanov, M. Y. Yerlukina and G. G. Fillipov, "The Methods of Linear Algebra in Physical Chemistry," in Russian, Publishing Moscow State University, Moscow, 1976, p. 360 .

[6] V. I. Shmuriov, "Introduction in Mathematical Programming," in Russian, Institute of Computer Researches, Moscow, 2002, p. 192.

[7] T. L. Wood and R. M. Garrels, "Thermodynamic Values at Low Temperature for Natural Inorganic Materials," Oxford University Press, Oxford, 1987, p. 265.

[8] A. A. Ravdel and A. M. Ponomariova, "The Brief Handbook of Physico-chemical Data,” in Russian, Khimiya, Leningrad, 1983, p. 232.

[9] L. P. Ogorodova, L. V. Melchakova and I. A. Kiseleva, "A Study of Dachiardite, a Natural Zeolite of the Mordenite Group,” in Russian, Zhurnal Fizicheskoy Khimii, Vol. 81, No. 11, 2007, pp. 1953-1955.

[10] E. C. Moloy, Q. Liu and A. Navrotsky, "Formation and Hydration Enthalpies of the Hydrosodalite Family of Materials," Microporous and Mesoporous Materials, Vol. 88, No. 1-3, 2008, pp. 283-292. doi:10.1016/j.micromeso.2005.09.020

[11] V. V. Bakakin and Yu. V. Seryotkin, "Unified Formula and Volume Characteristics in Comparative Crystal Chemistry of Natural Zeolites," Journal of Structural Chemistry, Vol. 50, No. 1, 2009, pp. 116-123. doi:10.1007/s10947-009-0199-4

[12] L. Mercury, Ph. Vieillard and Y. Tardy, "Thermodynamics of Ice Polymorphs and "ice-like" water in hydrates and hydroxides," Applied Geochemistry, Vol. 16, No. 2, 2001, pp. 161-181. doi:10.1016/S0883-2927(00)00025-1 